\title{
BMJ Open Cross-sectional survey of orthotic service provision in the UK: does where you live affect the service you receive?
}

\author{
Nachiappan Chockalingam (D) , ${ }^{1}$ Nicola Eddison, ${ }^{1,2}$ Aoife Healy (D) ${ }^{1}$
}

To cite: Chockalingam N, Eddison N, Healy A. Crosssectional survey of orthotic service provision in the UK: does where you live affect the service you receive? BMJ Open 2019;9:e028186. doi:10.1136/ bmjopen-2018-028186

- Prepublication history and additional material for this paper are available online. To view these files, please visit the journal online (http://dx.doi org/10.1136/bmjopen-2018028186).

Received 29 November 2018 Revised 18 August 2019 Accepted 07 October 2019

Check for updates

(C) Author(s) (or their employer(s)) 2019. Re-use permitted under CC BY-NC. No commercial re-use. See rights and permissions. Published by BMJ.

${ }^{1}$ Centre for Biomechanics and Rehabilitation Technologies,

Staffordshire University, Stoke on Trent, UK

${ }^{2}$ Orthotics Service, The Royal Wolverhampton NHS Trust,

Wolverhampton, UK

Correspondence to

Dr Aoife Healy;

a.healy@staffs.ac.uk

\section{ABSTRACT}

Objective To investigate the quantity and quality of orthotic service provision within the UK.

Design Cross-sectional survey obtained through freedom of information request in 2017.

Setting National Health Service (NHS) Trusts/Health Boards (HBs) across the UK.

Main outcome measures Descriptive statistics of survey results, including information related to finance, volume of appointments, patients and orthotic products, waiting times, staffing, complaints, outcome measures and key performance indicators.

Results Responses were received from 61\% (119/196) of contacted Trusts/HBs; $86 \%$ response rate from Scotland (12/14) and Wales (6/7), 60\% (3/5) from Northern Ireland and $58 \%$ (98/170) from England. An inhouse service was provided by $32 \%$ (35/110) of responses and $68 \%(74 / 110)$ were funded by a block contract. Long waiting times for appointments and lead times for footwear/orthoses, and large variations in patient entitlements for orthotic products across Trusts/HBs were evident. Variations in the length of appointment times were also evident between regions of the UK and between contracted and inhouse services, with all appointment times relatively short. There was evidence of improvements in service provision; ability for direct general practitioner referral and orthotic services included within multidisciplinary clinics. However, this was not found in all Trusts/HBs.

Conclusions The aim to provide a complete UK picture of orthotic service provision was hindered by the low response rate and limited information provided in some responses, with greater ability of Trusts/HBs to answer questions related to quantity of service than those that reflect quality. However, results highlight the large discrepancies in service provision between Trusts/HBs, the gaps in data capture and the need for the UK NHS to establish appropriate processes to record the quantity and quality of orthotic service provision. In addition to standardising appointment times across the NHS, guidelines on product entitlements for patients and their lead times should be prescribed to promote equity.

\section{INTRODUCTION}

Orthotic services within the UK National Health Service (NHS) provide assistive devices (eg, insoles, braces, splints and footwear) which help people recover from or avoid further injury or people who live with
Strengths and limitations of this study

- National cross-sectional survey, obtained through a freedom of information request, examining orthotic service provision in the UK's National Health Service.

- In January 2017 a survey was sent to all 196 Trusts/ Heath Boards who provided orthotic services.

- This cross-sectional survey gathered information on five areas of orthotic service provision (finance, service provision, staffing, complaints, and outcome measures and key performance indicators (KPIs)).

- This survey received a higher response rate $(61 \%)$, than a previous freedom of information request in $2014(29 \%)$

- The ability to provide a complete national picture of orthotic service provision was hindered by a low response rate.

chronic conditions, and these services are provided by orthotists and other healthcare professionals (eg, podiatrists, physiotherapists and occupational therapists). Orthotists are normally trained with a dual qualification, with graduates certified to practise as both orthotists and prosthetists; in the UK most will practise as either an orthotist or prosthetist with few practising in both areas. Orthotic services are in higher demand with at least two to four times more people attending services for orthotic treatment than for prosthetic treatment. ${ }^{1}$ Prosthetist and orthotist $(\mathrm{P} \& \mathrm{O})$ are protected titles in the UK and currently there are 1108 registered (as of 30 April 2019). ${ }^{2}$ A report by the British Association of Prosthetists and Orthotists (BAPO) in 2005 concluded that there should be a ratio of 1 orthotist per 30555 population. ${ }^{3}$ With the current UK population at 66 million this equates to a current shortage of $\mathrm{P} \& O$ s which are included on the UK Migration Advisory Committee Shortage Occupation List. Lack of access to prosthetic and orthotic services is a global issue; currently it is estimated that only $5 \%-15 \%$ (approximately 1 in 10 persons) of the world's population in need has access to prosthetic and orthotic devices. ${ }^{4}$ In 2017 , 
WHO, in partnership with the International Society for Prosthetics and Orthotics and the United States Agency for International Development, published global standards for prosthetics and orthotics ${ }^{56}$ which aim to ensure prosthetic and orthotic services are integrated into health services and systems. This global shortfall in access to orthotic services will be magnified in the future as the projected population growth and ageing population will result in an increase in demand. ${ }^{7}$

Orthotic service provision within the NHS has been described as a 'Cinderella service', ${ }^{89}$ poorly understood and low in any list of priorities. Taking the treatment of diabetic foot ulceration as an example, the importance of pressure-offloading, both non-removable (eg, total contact cast) and removable offloading devices (eg, footwear and removable cast walkers), in ulcer management is outlined within National Institute for Health and Care Excellence and International Working Group on the Diabetic Foot. ${ }^{10}{ }^{11}$ However, recent research examining patterns of care within the NHS identified that only $5 \%$ of patients with a diabetic ulcer received a pressure-offloading device. ${ }^{12}$ Data on orthotic service provision in the UK is lacking, with a report by the NHS Quality Observatory highlighting the current challenges in obtaining accurate figures, which included coding issues and poor recording. ${ }^{13}$ Although other allied health professions (such as occupational therapists, physiotherapists, podiatrists, and speech and language therapists) have reference costs within NHS systems, these are not available for orthotist appointments. ${ }^{14}$ While accurate data on the number of orthotic users in the UK is not available from the NHS, a report by the Foundation for Assistive Technology stated that there were approximately 1.2 million orthotic users in England in $2007,{ }^{15}$ while a report in 2011 estimated the number of users at 2 million. ${ }^{16}$ Problems within orthotic service provision in the UK have been the focus of a number of reports by the NHS ${ }^{39131718}$ and other organisations ${ }^{8}{ }^{19-22}$; with reports highlighting the 'case for action' and the many potential benefits of improving orthotic services, including clinical benefits for patients, financial benefits for the NHS and economic benefits for the wider economy. ${ }^{9}$ An NHS report in 2014 identified that there was a lack of parity and equity in orthotic service provision, ${ }^{13}$ and many patients who require orthotic services can find themselves waiting a long time for treatment which can lead to the development of secondary health complications. ${ }^{9}$ There is a need to accurately collect and use data on process, outcome and patient experiences of orthotic services which can be regularly monitored and reviewed to assess quality and identify areas of best practice. ${ }^{13}$

As a result of the lack of available data on orthotic service provision within the NHS both the NHS Quality Observatory and NHS England reports ${ }^{913}$ used data from a freedom of information (FOI) request titled "NHS National Orthotic Service Questionnaire" undertaken by the Medway NHS Foundation Trust in 2014, which highlighted significant variation in provision across the UK, to support their reports. That FOI received a $29 \%$ response rate $(55 / 188$ responses) from the surveyed services in England, Wales and Scotland; no responses were received from Northern Ireland's services. Due to ongoing anecdotal evidence of poor orthotic service provision in some areas of the UK, the aim of this study was to explore the current state of orthotic service provision from an organisational and management perspective. In 2017 a survey was undertaken, through a FOI request, to gain an understanding of current orthotic service provision in the UK, explore changes in service provision across the previous 5 years (2011-2016) and to establish the current state of regional differences in provision.

\section{METHODS}

In January 2017, identical FOI requests were sent to all Trusts in England and Northern Ireland and Health Boards (HBs) in Wales and Scotland; these are organisations within the NHS generally serving either a geographical area or a specialised function who provide orthotic services in the UK, a total of 196 Trusts/HBs.

The request consisted of a survey with 30 questions (see online supplementary file 1), designed to gather information on orthotic service provision and consisted of five sections: (1) finance, (2) service provision, (3) staffing, (4) complaints and (5) outcome measures and key performance indicators (KPIs). For some questions the Trusts/ HBs were asked to provide information for each of the five previous years $(2011 / 2012,2012 / 2013,2013 / 2014$, $2014 / 2015,2015 / 2016)$. The development of the survey questions was supported by previous FOI requests in this area (see online supplementary files 2 and 3 ), and it was piloted with two practising orthotists.

\section{Finance}

This section established how the Trusts/HBs orthotic service was run, the volume of orders and average lead time for orthotic products (survey focused on lower limb orthotic products) and the service's financial performance. Trusts/HBs were asked to state if they provided an inhouse or a contracted service; an inhouse service is one in which the orthotists are directly employed by the Trusts/HBs, while a contracted service is one in which an external company is contracted to provide orthotists and manage the service. They were also asked to state how the service was commissioned; whether through a block contract (contract is paid in advance of the service being undertaken and the value of the contract is independent of the actual number of patients treated or the amount of activity undertaken) or a local tariff ('per patient' tariff with set prices and rules). This question was not relevant to NHS Scotland HBs where a local tariff was not applicable.

\section{Service provision}

This section was designed to gain information on the volume of appointments and patients seen and the did 
not attend (DNA) rate within the orthotics service in each of the last 5 years (2011-2016), the current waiting times, involvement in multidisciplinary clinics and available facilities for patient assessment.

\section{Staffing}

The aim of this section was to gain information on staffing within the service, exploring the number, NHS banding and postgraduate training of the orthotists, the number of current staff vacancies and the employment of locum/ agency orthotists within the service.

\section{Complaints}

The section aimed to gather data on the volume of formal and informal complaints and orthotic related incidents within the service in each of the last 5 years (2011-2016).

\section{Outcome measures and KPIs}

The aim of this section was to gain information on how the service measured its performance, establishing the outcome measures and KPIs used within the service.

FOI requests should be responded to within 20 working days, to allow for a maximum number of responses to be included a deadline of 2 June 2017 for including responses was set. No follow-up contact to Trusts/HBs who did not respond to the FOI request was carried out. The results were analysed using descriptive statistics; providing counts, percentages, ranges and means.

\section{Patient involvement}

No patients were involved in the design, implementation or analysis of results of the study.

\section{RESULTS}

The FOI request was sent to a total of 196 Trusts/HBs; with $119(61 \%)$ responding, $20(10 \%)$ declining to reply and $57(29 \%)$ not responding. The response rates for the FOI request for each region (ranked by $\%$ response rate) were: Scotland 12 of 14 Trusts/HBs (86\% response rate), Wales 6 of 7 Trusts/HBs (86\%), Northern Ireland 3 of 5 Trusts/HBs (60\%) and England 98 of 170 Trusts/HBs $(58 \%)$.

In the subsequent analysis responses from 10 Trusts/ HBs from England and 1 from Wales were excluded as they stated that their Orthotics Service was run within another service and their survey response provided limited information. Within the 88 included responses from English Trusts, 1 Trust provided separate responses for their adult and paediatric services, and 1 Trust sent two individual replies for different geographical areas within their Trust; therefore, the total responses for England in the following analysis is quantified as 90 , and the total responses for the FOI as 110 . Of the responses that could be analysed, totalling $55 \%$ of the contacted Trusts/HBs, answers were not provided to all questions by all Trusts/HBs, with large variations in response rates across the thirty questions. The response rates to each individual question within the survey are provided in online supplementary file 4 .
Where percentages are presented, these were calculated based on the number of responses received for individual questions.

Although one could explore the reasons for Trusts/ HBs not responding to the request, which is beyond the scope of this commentary, we assessed the responses in a systematic way. Differences between regions of the UK were evident not only for the response rate of the FOI request but also for the response rate of individual questions within the FOI request.

\section{Finance}

Across the UK, the number of Trusts/HBs which provided an inhouse service were much lower $(32 \%$ of Trusts/HBs) than those that provided a contracted service $(68 \%)$. The percentage of inhouse services for each region was: $30 \%$ for England, $50 \%$ for Scotland, $40 \%$ for Wales and $0 \%$ for Northern Ireland. The majority (69\%; $92 \%$ response rate) of Trusts/HBs who responded were funded by a block contract. A question about financial performance was included in the FOI request, however, as the response rate for this question was so low and from some Trusts/HBs it was unclear whether the figures provided were per annum or per contract; it was not possible to analyse this data. The response rate for this question increased from $38 \%$ in 2011 to 55\% in 2016, with none of the Northern Ireland Trusts/HBs providing this information.

Trusts/HBs were asked to provide information on the volume of lower limb orthotic products they provided over the last 12 months (2015-2016). Many Trusts/HBs replied that they did not record this information; the response rate varied from $41 \%-59 \%$ across the different lower limb orthotic products (table 1). Trusts/HBs were also asked to provide their average lead time for these products with large variances evident across responses (figures 1 and 2, table 1). The largest variation was seen for the provision of bespoke ankle-foot orthoses (AFOs). The annual total spending on orthotic product and service from 2011 to 2016 are provided in table 2.

\section{Service provision}

Trusts/HBs were asked to provide information on the number of appointments and patients within the service over the past 5 years (2011-2016) and to provide a breakdown of the adult and paediatric appointments (table 3). The ability of Trusts/HBs to answer these questions improved over the 5-year period. However, there were still many Trusts/HBs who do not record data for paediatric patients separately. It was found that $33 \%$ of responding Trusts/HBs (35/105) used separate paediatric clinics for paediatric patients. The DNA rate remained consistent over the 5 -year period at $8 \% \pm 3 \%$, and the response rate for this question increased from $51 \%$ in 2011-2012 to $78 \%$ in 2015-2016.

A relatively high percentage of Trusts/HBs $(41 \%$ in England, $50 \%$ in Scotland and $100 \%$ in Northern Ireland) reported that they do not include their orthotics 
Table 1 Volume of lower limb orthotic products ordered and average and range for lead times in the UK (2015-2016)

\begin{tabular}{|c|c|c|c|}
\hline $\begin{array}{l}\text { Orthotic product } \\
\text { Response \% (no of Trusts/ } \\
\text { Health Boards who } \\
\text { responded) }\end{array}$ & $\begin{array}{l}\text { Total } \\
\text { volume of } \\
\text { orders }\end{array}$ & $\begin{array}{l}\text { Lead time: } \\
\text { average } \\
\text { (weeks)* }^{\text {(week }}\end{array}$ & $\begin{array}{l}\text { Lead time: } \\
\text { median } \\
\text { (weeks)† }\end{array}$ \\
\hline $\begin{array}{l}\text { Moulded EVA insoles } \\
45(49 / 110)\end{array}$ & 51326 & $3 \pm 2$ & $2.6(1-17.07)$ \\
\hline $\begin{array}{l}\text { Orthotic footwear repairs } \\
59(65 / 110)\end{array}$ & 30690 & $2 \pm 1$ & $2(0.6-10)$ \\
\hline $\begin{array}{l}\text { Modular adult orthotic } \\
\text { footwear } \\
51(56 / 110)\end{array}$ & 29469 & $5 \pm 2$ & $4(1.42-14.6)$ \\
\hline $\begin{array}{l}\text { Bespoke AFOs } \\
51(56 / 110)\end{array}$ & 21798 & $3 \pm 4$ & $1-34.65$ \\
\hline $\begin{array}{l}\text { Stock paediatric footwear } \\
51(56 / 110)\end{array}$ & 15186 & $3 \pm 2$ & $2.7(0.2-9)$ \\
\hline $\begin{array}{l}\text { Bespoke orthotic footwear } \\
54(59 / 110)\end{array}$ & 12255 & $6 \pm 3$ & $6(1.56-20)$ \\
\hline $\begin{array}{l}\text { Carbon fibre insoles } \\
41(45 / 110)\end{array}$ & 6347 & $3 \pm 1$ & $2(1-6.4)$ \\
\hline $\begin{array}{l}\text { Plastic heel cups } \\
41(45 / 110)\end{array}$ & 4514 & $3 \pm 2$ & $2.8(0.14-11)$ \\
\hline Total & 171585 & & \\
\hline
\end{tabular}

${ }^{*}$ mean \pm SD.

†Median (min-max)

AFO, ankle-foot orthosis; EVA, ethylene-vinyl acetate.

service as part of the 18-week referral to treatment (RTT) pathway; it is set out that patients should wait no longer than 18 weeks from general practitioner RTT in England, Scotland and Northern Ireland. ${ }^{23}{ }^{24}$ The 18-week RTT pathway was not an NHS Wales target for orthotic services. Seventy-five per cent of responding Trusts/HBs provided information on their current waiting times (adult/paediatric routine and urgent), and the data showed large variation across responses (figure 3 ).

Regarding orthotic services participating in multidisciplinary clinics, the response rate for this question was high (98\%). In Scotland and Wales all HBs who responded reported that their orthotists took part in these clinics. The English Trusts reported that $84 \%$ of orthotists within inhouse services $(21 / 25)$ and $83 \%$ of orthotists within contracted service $(52 / 63)$ took part in multidisciplinary clinics, leaving 15 Trusts which reported not taking part in multidisciplinary clinics. Two of the three Northern Ireland Trusts/HBs who responded to the FOI request reported taking part in these clinics.

The response rate for the question requesting information on the facilities (three-dimensional (3D) gait laboratory, two-dimensional (2D) video vector analysis, video analysis and other gait analysis facilities) available for patient assessments was high (95\%); 85\% of responding Trusts/HBs reported not having access to a 3D gait analysis laboratory or a 2D video vector analysis system and $79 \%$ of Trusts/HBs reported not having access to simple video analysis.

Based on the data provided in the responses, we estimated the average time per appointment for the year 2015-2016; data provided by the Trusts/HBs on the total number of orthotic sessions per week and the total number of appointments was used for this calculation (see online supplementary file 5). In both England and Scotland, the estimated time per appointment for inhouse services was longer (England $33 \mathrm{~min}$ and Scotland 41

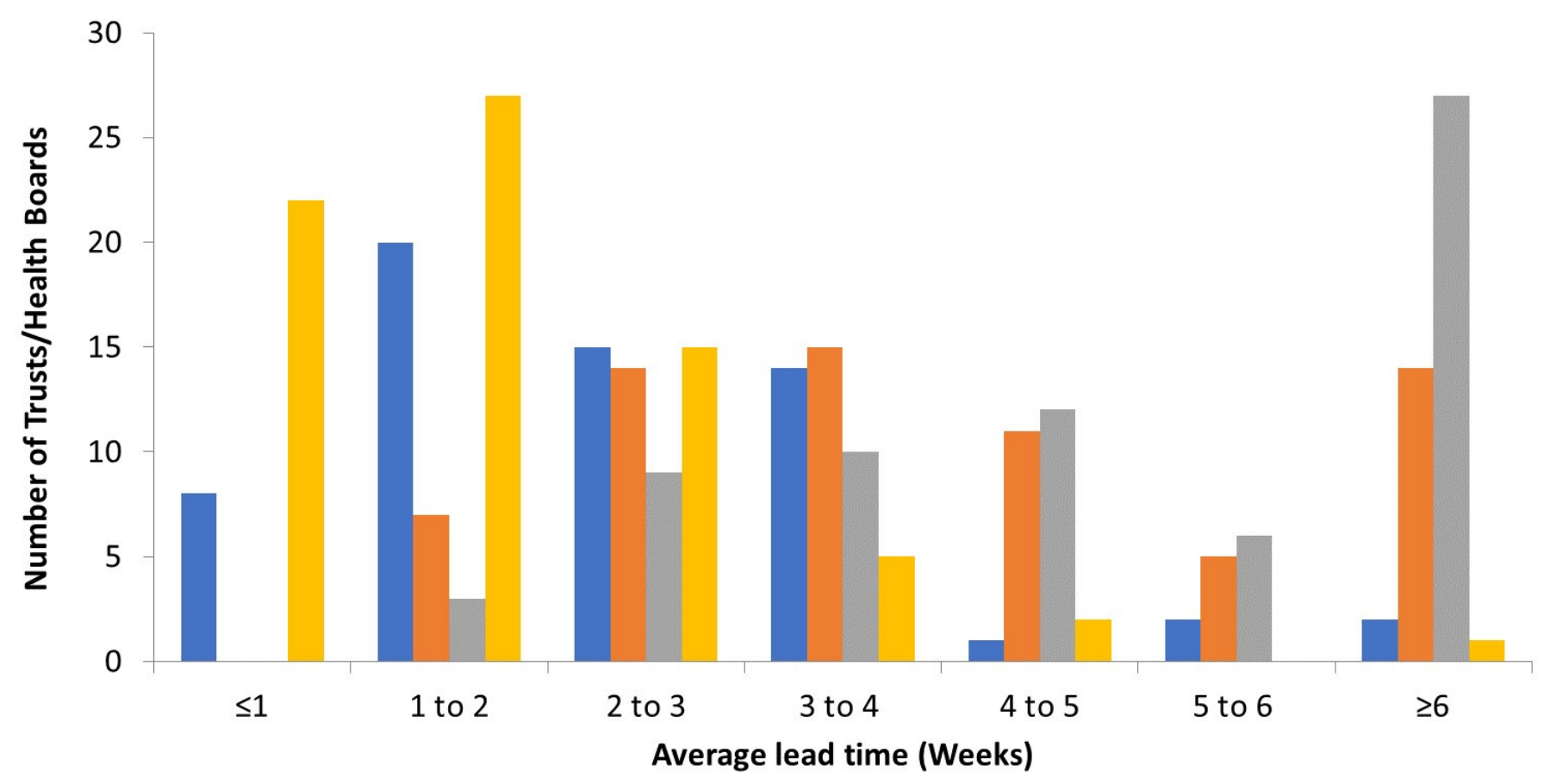

Stock paediatric footwear Modular adult orthotic footwear $\quad$ Bespoke orthotic footwear $\quad$ Orthotic footwear repairs Figure 1 Average lead time in weeks for footwear in the UK (2015-2016). 


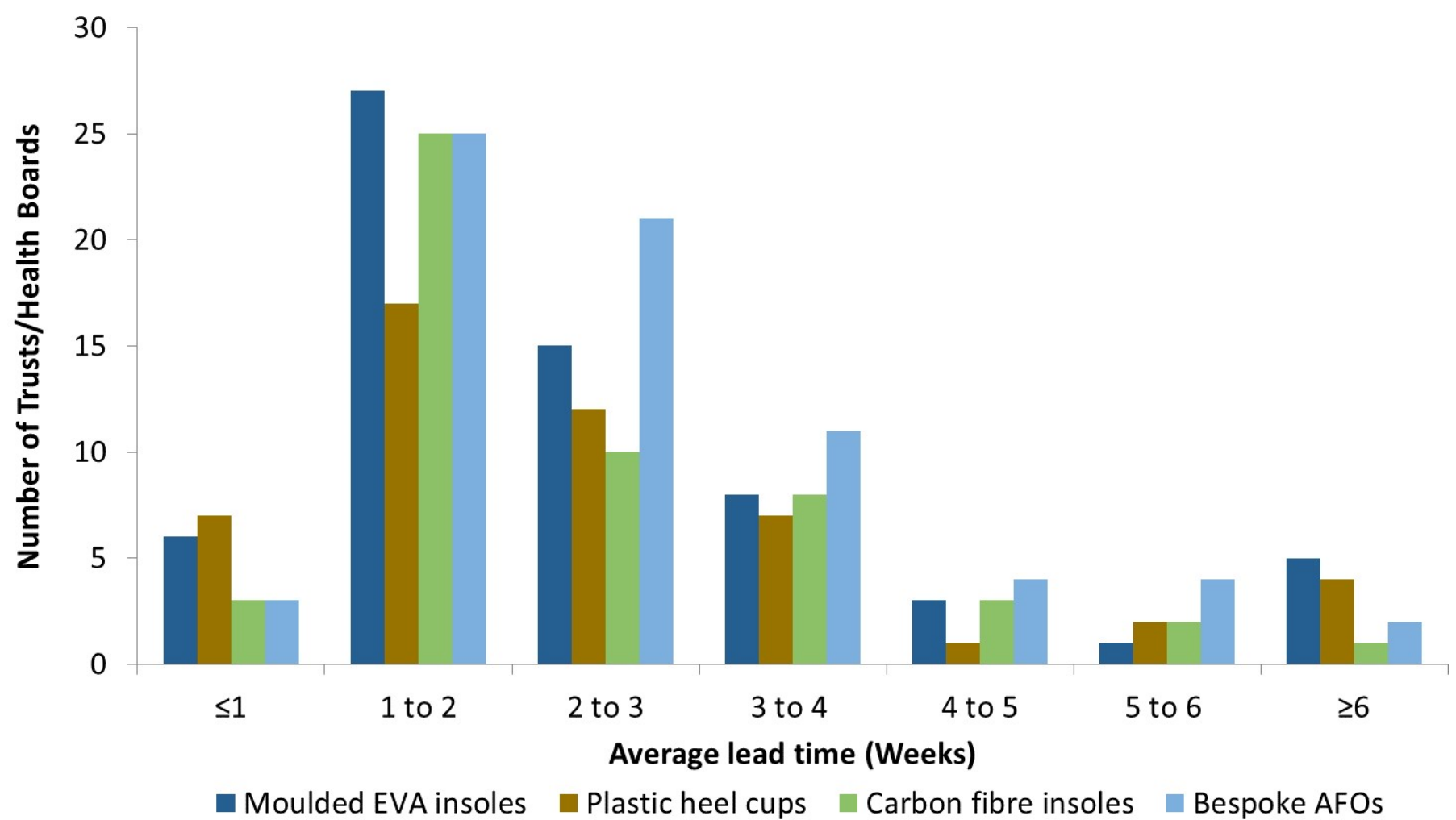

Figure 2 Average lead time in weeks for foot orthoses and AFOs in the UK (2015-2016). AFO, ankle-foot orthoses; EVA, ethylene-vinyl acetate.

min) than for contracted services (England 18 min and Scotland $24 \mathrm{~min}$ ). The time per appointment for inhouse and contracted services in Wales were 30 and $35 \mathrm{~min}$, respectively, and for Northern Ireland it was $21 \mathrm{~min}$.

\section{Staffing}

Trusts/HBs were asked to provide information on the number of sessions (both orthotist sessions and limited orthotic practitioner sessions) per week; limited orthotic practitioner's work in a limited area, having gained specific training in competency to assess for and fit a limited number of orthoses, under the supervision of an orthotist. They were also asked to provide information on the number of full-time equivalent orthotists and administration staff working within their orthotics service in 2015-2016. All Trusts/HBs in Scotland, Wales and Northern Ireland responded to this question, but within the English Trusts/HBs $78 \%$ of inhouse services and between $65 \%$ and $95 \%$ of contracted services provided responses to these questions. A total of 2123 orthotist sessions and 144 limited orthotic practitioner sessions per week were reported with 262 full time equivalent orthotists and 317 administration staff employed within the orthotic services.

Regarding the question on the clinical background of the manager of the orthotics services the response rate was high (93\%). Approximately $80 \%$ of managers had

\begin{tabular}{|c|c|c|c|}
\hline $\begin{array}{l}\text { Year } \\
\text { Response \% (no of Trusts/Health } \\
\text { Boards that responded) }\end{array}$ & Orthotic product & $\begin{array}{l}\text { Orthotic service (excluding } \\
\text { all non-pay items) }\end{array}$ & Total \\
\hline $\begin{array}{l}2011-2012 \\
38(42 / 110)\end{array}$ & $£ 21656333$ & $£ 9033775$ & $£ 30690108$ \\
\hline $\begin{array}{l}2012-2013 \\
43(47 / 110)\end{array}$ & $£ 24469684$ & $£ 10677239$ & $£ 35146923$ \\
\hline $\begin{array}{l}2013-2014 \\
48(53 / 110)\end{array}$ & $£ 27785999$ & $£ 12822933$ & $£ 40608932$ \\
\hline $\begin{array}{l}2014-2015 \\
53(58 / 110)\end{array}$ & $£ 32021319$ & $£ 14589447$ & $£ 46610766$ \\
\hline $\begin{array}{l}2015-2016 \\
55(60 / 110)\end{array}$ & $£ 34342895$ & $£ 14320940$ & $£ 48663835$ \\
\hline
\end{tabular}


Table 3 Total (adult and paediatric) and paediatric number of appointments and patients within the service from 2011 to 2016

\begin{tabular}{|c|c|c|}
\hline Year & $\begin{array}{l}\text { Number of } \\
\text { appointments } \\
\text { Response } \\
\% \text { (no of } \\
\text { Trusts/Health } \\
\text { Boards who } \\
\text { responded) }\end{array}$ & $\begin{array}{l}\text { Number of } \\
\text { patients } \\
\text { Response } \\
\% \text { (no of } \\
\text { Trusts/Health } \\
\text { Boards who } \\
\text { responded) }\end{array}$ \\
\hline 2011-2012 & $\begin{array}{l}495279 \\
61(67 / 110)\end{array}$ & $\begin{array}{l}313239 \\
56(62 / 110)\end{array}$ \\
\hline Paediatric & $\begin{array}{l}74613 \\
47(52 / 110)\end{array}$ & $\begin{array}{l}47382 \\
47(52 / 110)\end{array}$ \\
\hline 2012-2013 & $\begin{array}{l}552206 \\
67(74 / 110)\end{array}$ & $\begin{array}{l}371484 \\
64(70 / 110)\end{array}$ \\
\hline Paediatric & $\begin{array}{l}92753 \\
45(50 / 110)\end{array}$ & $\begin{array}{l}58130 \\
54(59 / 110)\end{array}$ \\
\hline \multirow[t]{2}{*}{ 2013-2014 } & $\begin{array}{l}618954 \\
73(80 / 110)\end{array}$ & $\begin{array}{l}421515 \\
70(77 / 110)\end{array}$ \\
\hline & $\begin{array}{l}109315 \\
59(65 / 110)\end{array}$ & $\begin{array}{l}74199 \\
59(65 / 110)\end{array}$ \\
\hline 2014-2015 Total & $\begin{array}{l}689493 \\
82(90 / 110)\end{array}$ & $\begin{array}{l}458354 \\
81(89 / 110)\end{array}$ \\
\hline Paediatric & $\begin{array}{l}120384 \\
67(74 / 110)\end{array}$ & $\begin{array}{l}84202 \\
67(74 / 110)\end{array}$ \\
\hline 2015-2016 Total & $\begin{array}{l}726947 \\
85(94 / 110)\end{array}$ & $\begin{array}{l}459212 \\
81(89 / 110)\end{array}$ \\
\hline Paediatric & $\begin{array}{l}129019 \\
69(76 / 110)\end{array}$ & $\begin{array}{l}87798 \\
68(75 / 110)\end{array}$ \\
\hline
\end{tabular}

a clinical background (40\% orthotist, $15 \%$ podiatrist, $13 \%$ physiotherapist, $5 \%$ occupational therapist and $7 \%$ other). There were more managers who were orthotists within the inhouse than the contracted services within England (68\% inhouse (17/25 Trusts/HBs); $27 \%$ contracted (16/59)) and Scotland (100\% Inhouse $(5 / 5)$; $60 \%$ contracted $(3 / 5))$.

When asked to provide details of the NHS Banding, or equivalent, of the orthotists within the services the response rate was low $(50 \%)$, with most Trusts/HBs who had contracted services stating that the question was not applicable to them as the service was contracted.

Trusts/HBs were asked if orthotists working with complex and highly complex conditions already have or are provided with additional postgraduate training in orthotic management of these conditions. The overall response rate for the UK was $79 \%$; $22 \%$ of responding Trusts/HBs stated that mandatory training was provided, $55 \%$ stated it was provided but not mandatory, and $23 \%$ stated that it was not provided. The Scottish Trusts/HBs reported the highest rates of postgraduate training for complex conditions $(100 \%$ for contracted services and $80 \%$ for inhouse services), the lowest response rate for this question $(70 \%)$ was for English Trusts/HBs with a contracted service.

Regarding the provision of protected time for continued professional development (CPD), there was a response rate of $76 \%$ across the UK. The lowest response rates were from Trusts/HBs using a contracted service (England 67\% (42/63 Trusts/HBs), Scotland 67\% (4/6) and Wales $67 \%(2 / 3))$. The reported CPD time ranged from 1 hour to $>6$ hours per month, with the greatest number of Trusts/HBs selecting that they provide 3 hours (13 Trusts/HBs) or 4 hours (15 Trusts/HBs) per month. Six Trusts/HBs stated providing CPD on an ad hoc basis and 23 Trusts/HBs responded that their orthotists did not have protected CPD time.

Regarding vacancies for orthotists at the time of the survey a response was provided by $61 \%$ of Trusts/HBs. Of the responding Trusts/HBs $19 \%$ reported that they

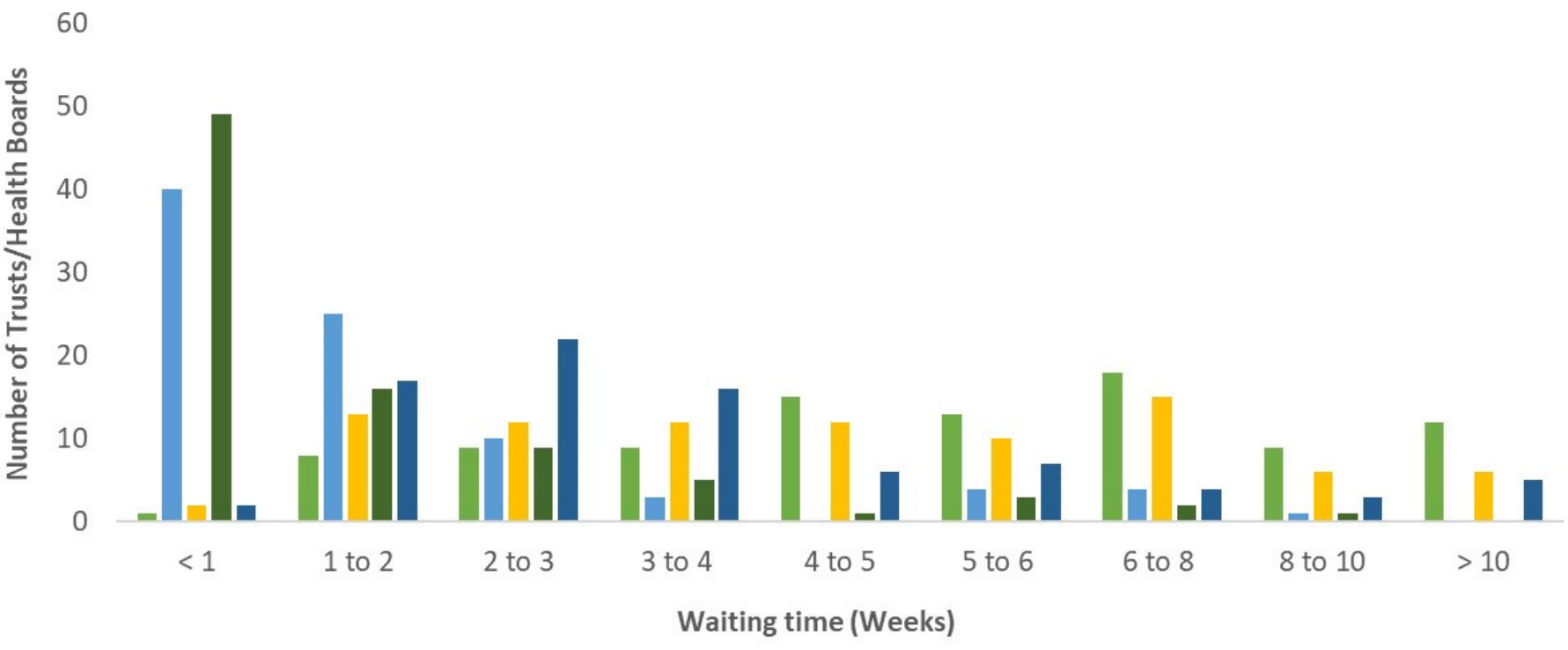

Adult urgent

- Paediatric routine

Paediatric urgent

Paediatric AFO

Figure 3 Average waiting times in weeks in the UK (January 2017). AFO, ankle-foot orthosis. 
had vacancies, and when asked why the position had not been filled some commented on a lack of applicants for positions. Regarding the question about the employment of locum orthotists (91\% of responding Trusts/ HBs answered this question); 21 of the 100 Trusts/HBs who responded stated that they were currently employing locum/agency orthotists and 40 Trusts/HBs stated they had employed locum/agency orthotists over the last 5 years (2011-2016).

\section{Complaints}

Trusts/HBs were asked to provide a breakdown of the number of formal and informal complaints they had received regarding their orthotic service in the previous 5 years (2011-2016). The complaints data gives insight into the number of patients who were dissatisfied with their orthotics service to an extent that they felt it necessary to raise either an informal or a formal complaint with the Trust. The response rate for this question increased from $72 \%$ in 2011 to $85 \%$ in 2016 for formal complaints and from $55 \%$ in 2011 to $65 \%$ in 2016 for informal complaints. The total number of formal and informal complaints increased annually from 130 and 83 in 2011, to 182 and 328 in 2016, respectively. They were also asked to report how many orthotic related incidents had been logged on their incident reporting system annually over the 5-year period; this increased from 138 (65\% response rate) in 2011 to $318(75 \%)$ in 2016.

\section{Outcome measures and KPIs}

Patient satisfaction was monitored by $80 \%$ of responding Trusts/HBs (97\% response rate), and $35 \%$ of the responses stated that they used outcome measures to assess orthotic interventions (94\% response rate). The use of a wide range of outcome measures were reported; including function (assessed using various walking tests for example, $10 \mathrm{~m}$ walk test and Timed Up and Go Test (which assesses mobility and balance) and Berg Balance Scale (which assesses static and dynamic balance ability), and questionnaires and visual analogue scales to assess pain, comfort and quality of life. With regard to the question about KPIs, the response rate was high (94\%); Trusts/HBs were asked if they monitored routine waiting times $(70 \%$ responded yes), manufacturer lead times $(51 \%)$, inpatient waiting times $(27 \%)$, urgent waiting times $(30 \%)$ and failed first fits $(43 \%)$. When asked if they accepted general practitioner referrals, $85 \%$ of responding Trusts/HBs (89/105) responded that they accepted referrals via this route.

Trusts/HBs were asked if they had an orthotic service patient entitlement allowance for a range of orthoses (94\% response rate), with a varied response dependant on the type of orthosis (figure 4). Wide variation in entitlements were seen across Trusts/HBs, with some reporting 1 pair of footwear/orthoses or alteration per year or per shoe size for children, others two pairs/alterations and some stated orthoses were provided 'as needed'.

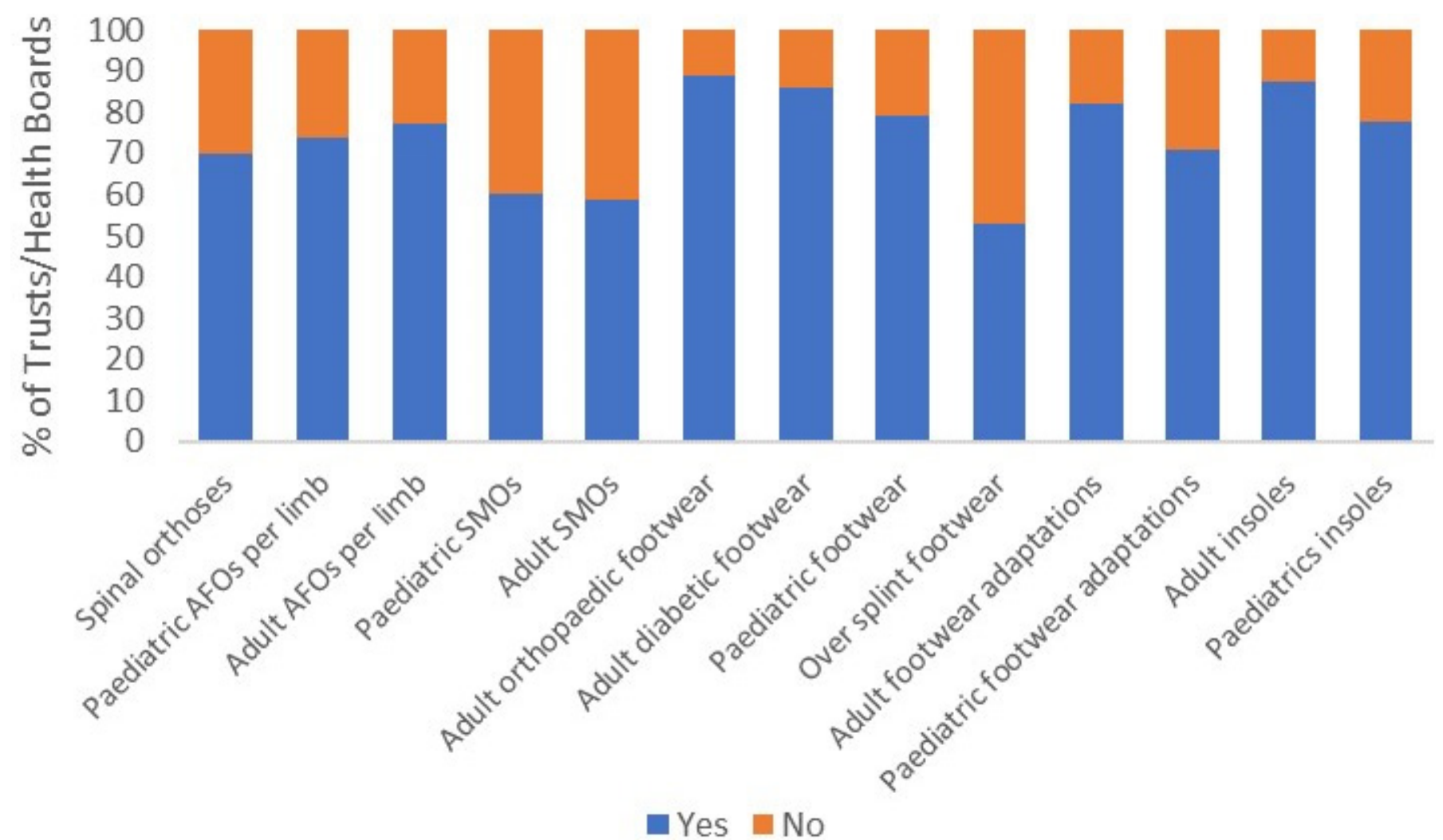

Figure 4 Percentage of Trusts/Health Boards which had an orthotic service patient entitlement allowance for orthoses (January 2017). AFO, ankle-foot orthosis; SMO, supramalleolar orthosis. 


\section{DISCUSSION}

This survey was undertaken to gain an understanding of current orthotic service provision in the UK. Results highlighted the large variances across Trusts/HBs; these variances included appointment times, waiting times, product entitlements for patients and product lead times.

Variances in appointment times were evident between regions and between contracted and inhouse services, with all appointment times relatively short (average times between 18 and $41 \mathrm{~min}$ ). This finding is confirmed by a recent study which examined foot orthotic provision in the United Kingdom ${ }^{25}$; reporting that the majority of orthotists $(62 \%)$ had $15-30$ min for clinical assessments and $15 \%$ reported having $<15 \mathrm{~min}$ appointments. These appointment times were significantly lower than those reported for podiatrists and physiotherapists, who were 11.0 and 13.2 times more likely, respectively, to have 45-60 min appointments. ${ }^{25}$ It also supports previous research which reported that when orthotists were asked if they provided AFO-footwear combination tuning 27\% said they did not tune due to a lack of time. ${ }^{26}$ These short appointment times, reported in the present survey and previous research, are below the recommended treatment times set out by BAPO; 20 min treatment blocks differentiated as: (1) initial assessment and analysis, (2) measurement and device specification, (3) trial evaluation of the device, (4) supply and final evaluation of the device, (5) review and fine tuning of treatment and (6) final review of treatment outcomes. ${ }^{27}$ They also advise that this treatment time may need to be increased to reflect the level of experience of the orthotist or the complexity of the case. The recommended treatment times are set by the BAPO Professional Affairs Committee which is a representative group including experienced senior clinicians from all four UK nations, with both NHS and contractor staff consulted. The committee also consider feedback received directly from members and statements made indirectly by clinicians in their biennial 'Working Practices' survey when setting the recommended treatment times. In light of this, while we could consider it as a negative that the survey showed that most Trusts/HBs did not have access to facilities for patient assessments, even simple video analysis, given the current short appointment times it would not be feasible for orthotists to use these facilities even if they could access them. As research has found that orthotists reported that they didn't have adequate time within appointments to complete AFO-footwear combination tuning, ${ }^{26}$ and that orthotists have significantly shorter appointment times than podiatrists and physiotherapists, ${ }^{25}$ further research is required to establish if orthotists working in the NHS have sufficient time to complete their patient assessments and design or evaluate a treatment plan.

There were large variations across Trusts/HBs for urgent waiting times for adult and paediatric appointments which are consistent with previous research. ${ }^{9}$ The majority of Trusts/HBs reported lead times which were outside what has been recommended as maximum reasonable timescales; 10 working days for an AFO, 25 working days for bespoke footwear and 15 working days or stock footwear. ${ }^{28}$ This combined with differences in patient entitlement confirm, as previously reported, ${ }^{28}$ that service provision varies according to where you live; there is a need for a national standard to promote equity of care.

Combined long waiting times for appointments and lead times for footwear/orthoses means extended time before treatment is received; the present survey reports average and maximum waiting times for adult appointments of 7 and 34 weeks, respectively, in January 2017. The Medway FOI reported average and maximum waiting times of 9 and 51 weeks, respectively, in $2013-2014 .{ }^{13}$ For paediatric patients average and maximum waiting times were 5 and 20 weeks, respectively, in contrast to 7 and 52-week waiting times reported elsewhere in 2013-2014. ${ }^{13}$ Survey results showed that some Trusts/HBs appeared to not accommodate the needs of children. Waiting times of 20 weeks for routine and 8.2 weeks for urgent appointments are unacceptable, as are the long waiting times for supply of paediatric AFOs, usually provided to children with long-term disabling conditions, reported as up to 20 weeks.

Potential reasons for the long waiting times may be due to Trusts/HBs not including orthotic services in the 18-week RTT target or it could be due to a shortage of orthotists or a combination of both. Minimum waiting times are particularly important for children, as long waiting times mean they may have outgrown an orthotic device by the time they receive it and industry standard lead times for orthotic products are required. In addition, the Special Educational Needs and Disability code of practice, ${ }^{29}$ produced by the UK government, outlines duties for commissioning services to improve outcomes for children and young people who have special educational needs or disabilities, excessive waiting times affects the Trusts/HBs' ability to provide orthotic services effectively to this patient group. There was an increase in the number of Trusts/HBs recording patient complaints and the DNA rate over the 5-year period, and the average DNA rate for orthotic services was consistent with the rate reported across the NHS. ${ }^{30}$

There was a high response rate $(97 \%)$ to the question about monitoring patient satisfaction, with $80 \%$ of responding Trusts/HBs including patient satisfaction as a KPI could be perceived as positive and will help in the improvement of service provision. However, there were large variances across Trusts/HBs, most responders reported monitoring routine waiting times with a low number of Trusts/HBs monitoring inpatient and urgent waiting times and failed first fits.

While the introduction of local tariffs has been recommended $^{9}$ most of the Trusts/HBs who responded were funded by a block contract $(69 \%$; 70/101). Many of the Trusts/HBs using a contracted service entered zero for the number of full-time orthotists who work within their Trusts/HBs. Possible explanations for this finding 
are that they did not consider this question relevant as their service was contracted, or that they do not know the number of orthotists who work within the service. Therefore, it appears that many Trusts/HBs do not hold information on the orthotists treating their patients. A positive response was that $77 \%$ of responding Trusts/ HBs reported that their orthotists working with complex conditions had postgraduate training in orthotic management of these conditions. However, the lowest response rate $(70 \%)$ for this question was from English Trusts/HBs with a contracted service, possibly indicating that these Trusts/HBs were not aware of the competency of the staff working with these patients. A lower response rate from Trusts/HBs with a contracted service was also evident for protected CPD time. A positive response was that $73 \%$ of responding Trusts/HBs reported providing protected CPD time for their orthotists, however it should be standard practice for all orthotists to receive protected CPD time across all Trusts/HBs.

It was reported in the NHS Quality Observatory ${ }^{13}$ that the volume of orthotic appointments and users was significantly under-reported within NHS systems; their review of Hospital Episode Statistics found 159729 orthotics attendances were recorded for 2013-2014. However, in contrast the Medway NHS Foundation Trust FOI reported that the 38 Trusts who responded to the question treated 208231 patients. In the present study, for the same year as presented in these previous reports (2013-14), the total volume of appointments and patients for the UK was significantly higher, at 618953 and 421515 , respectively (table 3 ). There is also a vast discrepancy between reports on the volume of orthotic users (which are all people who use an orthosis, not only people attending orthotic services); with estimated figures of between 1.2 million $^{15}$ and 2 million ${ }^{16}$ in England. This highlights the need for accurate information on the volume of patients attending orthotic services and on orthotic users in general; without this information it is not possible to provide and evaluate an effective orthotic service or to understand the scale of the need for orthoses.

For the questions which asked for information over the previous 5 years (2011-2016) there was an annual increase over the 5 years in the number of Trusts/HBs who provided responses, suggesting positive improvements in record keeping. However, this variance in response rate meant that it was not possible to directly compare across the years as it is not possible to determine if changes were as a result of changes within the orthotic services or as a result of the increased number of responses to the questions in the FOI. While in some instances it was possible to identify differences in service provision between regions, due to the low response rate for many questions it was not always possible to provide comparisons.

As previously discussed, a report by the NHS Quality Observatory $^{13}$ highlighted the current challenges in obtaining accurate figures for orthotic service provision; as these is limited historical data on this service this hinders comparison with findings from the present survey. A study by Fox and Winson in $1994^{31}$ reported that the annual NHS orthotics budget was approximately $£ 38$ million. While the method used to establish this figure differed to the method used within the present survey, it is postulated based on this information that the total budget for orthotic services doesn't seem to increase in proportion to the overall NHS spend; which has increased by approximately $4 \%$ a over the lifetime of the NHS. ${ }^{32}$ Our results show $£ 30.6$ million in 2011-2012 within the responding Trusts/HBs, which increases to $£ 40.6$ in 2013-2014 and £48.6 in 2015-2016 (table 2). The lack of difference within the period from 1994 to 2016 is even more significant considering that this comparison does not take inflation into consideration. This highlights a clear lack of overall understanding of the expenses. In addition, without a clear picture of income and expenditure it is difficult to show the cost effectiveness of the service provision.

The response to use of outcome measure was very disappointing, with only $35 \%$ of responding Trusts/ HBs (36/103) using outcome measures, implying that most Trusts/HBs have no formal method of measuring whether the orthotic intervention they have prescribed has been effective. For those Trusts/HBs who reported using outcome measures a wide selection of measures are stated as being used including various visual analogue scales, questionnaires and functional objective tests (eg, timed up and go). These findings are confirmed by recently published research conducted by BAPO; their survey of prosthetists and orthotists in the UK indicated that only $28 \%$ routinely used outcome measures, with no consistency in the outcome measures used. ${ }^{33}$ As previously reported, ${ }^{34}$ the use of a core set of patient-reported outcome measures would enable the assessment of the effectiveness of treatment interventions and would also facilitate audit.

The potential reasons for this finding are multifaceted, but the reported short appointment times and the lack of availability of essential equipment required to undertake accurate measurements in this survey could be important contributing factors. Previous research has reported that orthotists did not routinely provide AFO-footwear combination tuning, which includes essential aspects of orthotic provision such as static and dynamic alignments of orthoses, $27 \%$ said they did not tune due to a lack of time and they felt that they did not have the required equipment. ${ }^{26}$ While it is recognised that visual gait analysis is inaccurate ${ }^{3536}$ and that video gait assessment should be routine clinical practice for orthotic provision ${ }^{37}$ most Trusts/HBs do not provide access to simple and inexpensive digital slow-motion video analysis.

In 2014, an NHS report stated that it was not possible to obtain accurate figures on the number of people in England accessing orthotics services, with this issue attributed to the complexity of pathways of care and poor availability and accessibility of data. ${ }^{13}$ While the data presented from this survey is limited by the low response rates for some questions, the information gained provides 
a valuable insight into orthotic service provision in the UK. While the response rate for this survey was low $(61 \%$ of contacted Trusts/HBs responded), it received more replies than the Medway NHS Foundation Trust FOI request in 2014 which had a $29 \%$ response rate $(55 / 188$ organisations responded). ${ }^{9}$ Of the 20 Trusts/HBs who declined to reply 13 deemed that answering the request would cost in excess of $£ 450$ (Section 12 of the Freedom of Information $\mathrm{Act}^{38}$ ) which suggests there may be poor record keeping for orthotic service provision in these Trusts/HBs. Two Trusts/HBs declined due to commercial interests (Section $43^{38}$ ), yet as many other Trusts/ HBs responded to the FOI request it is unclear why they considered that they could not respond to the survey. Five Trusts/HBs declined as they stated that their service was contracted to an external company. However, even if the service was contracted, one can argue that the Trusts/HBs are still responsible for overseeing the service and therefore should have access to the requested information.

While this survey confirms that many of the issues reported in previous reports on orthotic service provision $^{8920}$ are still evident there were also improvements in service provision identified. The projected population growth, ageing population and rising prevalence of obesity, diabetes, cardiovascular and peripheral vascular diseases will result in an increased demand for orthotics services in the future, ${ }^{9}$ and therefore, it is essential to ensure that services are capable of meeting current and future demands. Although the low number of responses received could be seen as a limitation of this report; to improve orthotic service provision first it is necessary to fully understand current provision. This has been argued since the late $1980 \mathrm{~s},{ }^{39}$ however the change seems to be rather slow. Additional independent structured research and service evaluations sponsored by a competent authority (such as the Department of Health and Social Care) need to be commissioned which gather complete assessment of orthotic service provision across the UK.

\section{CONCLUSIONS}

The combination of the number of Trusts/HBs who declined to reply to the FOI request and those who replied but provided limited information in their reply hindered the ability to combine the data received to provide a complete national picture of orthotic service provision. Results from this survey highlight the large discrepancies in service provision (eg, waiting times for appointments and orthotic products) between Trusts/ HBs. There appeared to be a greater ability for Trusts/ HBs to answer questions that reflect quantity of service compared with questions that reflect quality of service. This report clearly highlights the gaps in terms of clinical and economic data capture which prevents the evaluation of effectiveness and cost effectiveness of service provision. The UK NHS needs to establish appropriate processes to record the quality of service provision to enable improvements in clinical management and to get good value for money.

Twitter Nachiappan Chockalingam @nachic

Acknowledgements We acknowledge the contribution of Elaine Owen who contributed to the study design, interpretation of the data and revision of draft manuscripts, and Thomas Perry who supported the data acquisition and analysis of the work.

Contributors NC and NE were responsible for the conception of the work, with all authors contributing to study design. $\mathrm{NC}$ and $\mathrm{AH}$ completed the data acquisition and analysis, with all authors involved in the interpretation of data. AH was responsible for the original drafting of the work with all authors revising it critically for important intellectual content. All authors had final approval of the version to be published. All authors agree to be accountable for all aspects of the work in ensuring that questions related to the accuracy or integrity of any part of the work are appropriately investigated and resolved.

Funding The authors have not declared a specific grant for this research from any funding agency in the public, commercial or not-for-profit sectors.

Competing interests None declared.

Patient consent for publication Not required.

Ethics approval An ethics disclaimer form for this study was submitted to the Staffordshire University Ethics Committee prior to the start of the study.

Provenance and peer review Not commissioned; externally peer reviewed.

Data availability statement The authors will not share the data for this work. The data for this work was obtained through a freedom of information request, with the responses from individual Trusts/Health boardspublicly available.

Open access This is an open access article distributed in accordance with the Creative Commons Attribution Non Commercial (CC BY-NC 4.0) license, which permits others to distribute, remix, adapt, build upon this work non-commercially, and license their derivative works on different terms, provided the original work is properly cited, appropriate credit is given, any changes made indicated, and the use is non-commercial. See: http://creativecommons.org/licenses/by-nc/4.0/.

ORCID iDs

Nachiappan Chockalingam http://orcid.org/0000-0002-7072-1271

Aoife Healy http://orcid.org/0000-0002-4948-6086

\section{REFERENCES}

1 International Committee of the Red Cross. Physical rehabilitation programme: annual report 2013, 2014. Available: https://www.icrc. org/en/publication/4209-physical-rehabilitation-programme-annualreport-2013 [Accessed 7 Nov 2018].

2 Health and Care Professions Council. Registrant snapshot - December 2018, 2019. Available: http://www.hpc-uk.org/ globalassets/resources/data/2018/registrant-snapshot-20181130.pdf

3 Scotland NHS. Scottish Orthotic services review, 2005. Available: https://www.sehd.scot.nhs.uk/publications/dc20050614orthotics.pdf [Accessed 8 Nov 2018].

4 Khasnabis C. Standards for prosthetics and Orthotics service provision: 2015-2017 work plan. version 4 2015, 2015. Available: http://www.who.int/phi/implementation/assistive_technology/ workplan_p-o_standards.pdf [Accessed 8 Nov 2018].

5 World Health Organization. Standards for prosthetics and Orthotics Part 1: standards. Available: 2017.http://apps.who.int/iris/bitstream/ handle/10665/259209/9789241512480-part1-eng.pdf;jsessionid= 4A15505E7D48A40246283DBF4A2DBB17? sequence $=1$ [Accessed 8 Nov 2018].

6 World Health Organization. Standards for prosthetics and Orthotics Part 2: implementation manual, 2017. Available: http://apps.who.int/ iris/bitstream/handle/10665/259209/9789241512480-part2-eng.pdf? sequence $=2$ [Accessed 8 Nov 2018].

7 Nielsen C. Issues affecting the future demand for Orthotists and Prosthetists, 2002. Available: http://www.ncope.org/summit/pdf/ Footnote3.pdf [Accessed 8 Nov 2018].

8 Solutions B. Orthotic Pathfinder: a patient focused strategy and proven implementation plan to improve and expand access to orthotic care services and transform the quality of care delivered, 2004. Available: http://www.bhta.net/sites/default/files/document- 
upload/2012/orthotic_pathfinder_report_july_2004.pdf [Accessed 1 Feb 2017].

9 England NHS. Improving the quality of Orthotics services in England, 2015. Available: https://www.england.nhs.uk/commissioning/wpcontent/uploads/sites/12/2015/11/orthcs-final-rep.pdf [Accessed 8 Nov 2018].

10 National Institute for Health and Care Excellence. Diabetic foot problems: prevvention and management. NICE guideline, 2015. Available: https://www.nice.org.uk/guidance/ng19/ resources/diabetic-foot-problems-prevention-and-management1837279828933 [Accessed 9 Nov 2018].

11 Bus SA, van Deursen RW, Armstrong DG, et al. Footwear and offloading interventions to prevent and heal foot ulcers and reduce plantar pressure in patients with diabetes: a systematic review. Diabetes Metab Res Rev 2016;32:99-118.

12 Guest JF, Fuller GW, Vowden P. Diabetic foot ulcer management in clinical practice in the UK: costs and outcomes. Int Wound $J$ 2018;15:43-52.

13 Chavda A, Cheema K. Analysing orthotics: availability of data and information in orthotics services in England. NHS Quality Observatory, Horley 2014.

14 Improvement NHS. Reference costs 2016/17, 2018. Available: https://improvement.nhs.uk/resources/reference-costs/ [Accessed 7 Nov 2018].

15 Down K, Stead A. Assistive technology workforce development, 2007. Available: http://www.fastuk.org/fastdocuments/AT_workforce June2007_v2.pdf [Accessed 8 Nov 2018].

16 GlobalData. Orthotics and Prosthetics - Global Pipeline Analysis, Competitive Landscape and Market Forecasts to 2017, 2011. Available: https://www.researchmoz.us/orthotics-and-prostheticsglobal-pipeline-analysis-competitive-landscape-and-marketforecasts-to-2017-report.html [Accessed 29 Oct 2018].

17 England HE. The Future of the Orthotic and Prosthetic Workforce in England. Response to the NHS England report 'Improving the Quality of Orthotic Services in England', 2017. Available: https://hee.nhs. uk/sites/default/files/documents/Orthotic Report Final Version_0.pdf [Accessed 8 Nov 2018].

18 England HE. The future of the prosthetic and Orthotic workforce in England: one year on, 2018. Available: https://hee.nhs.uk/sites/ default/files/documents/The future of the prosthetic and orthotic workforce in England - one year on.pdf [Accessed 8 Nov 2018].

19 Audit Commission. Fully equipped 2002: assisting independance 2002.

20 Hutton JL, Hurry M. Orthotic Service in the NHS - Improving Service Provision 2009.

21 Centre for Economics and Business Research. The economic impact of improved orthotic services provision, 2011. Available: http://www. bhta.net/sites/default/files/document-upload/2012/Orthotics_review_ Cebr_report_04_07_2011.pdf [Accessed 16 Jan 2017].

22 Arthritis Research UK.. A call to action: providing better footwear and foot orthoses for people with rheumatoid arthritis, 2012. Available: https://www.arthritisresearchuk.org/ /media/Files/Policy files/Policy pages files/Footwear_Report_ARUK (1).ashx?la=en [Accessed 8 Nov 2018].

23 Department of Health. The NHS Constitution - the NHS belongs to us all 2015. [Epub ahead of print: 26 March 2013].

24 NHS Scotland. 18 weeks: the referral to treatment standard 2008.

25 Nester CJ, Graham A, Martinez-Santos A, et al. National profile of foot orthotic provision in the United Kingdom, part 2: podiatrist, orthotist and physiotherapy practices. J Foot Ankle Res 2018;11:1-12.

26 Eddison N, Chockalingam N, Osborne S. Ankle foot orthosisfootwear combination tuning: an investigation into common clinical practice in the United Kingdom. Prosthet Orthot Int 2015;39:126-33.

27 British Association of Prosthetists and Orthotists. Standards for best practice 2018.

28 All-Party Associate Parliamentary Limb Loss Group. Patient led Orthotic services patients charter 2011

29 Department for Education,, Department for Health. Special educational needs and disability code of practice: 0 to 25 years 2015.

30 NHS England. Nhs inpatient admission and outpatient referrals and attendances, 2018. Available: https://www.england.nhs.uk/statistics/ wp-content/uploads/sites/2/2018/02/QAR-commentary-Q3-171878201-2.pdf [Accessed 8 Nov 2018].

31 Fox HJ, Winson IG. Foot orthoses: an audit of expenditure and efficacy. The Foot 1994;4:79-82.

32 The Health Foundation. Health and social care funding explained, 2017. Available: https://www.health.org.uk/chart/health-and-socialcare-funding-explained [Accessed 6 Jun 2019].

33 Young J, Rowley L, Lalor S. Use of outcome measures among Prosthetists and Orthotists in the United Kingdom. J Prosthetics Orthot 2018;30:152-7.

34 O'Connor J, McCaughan D, McDaid C, et al. Orthotic management of instability of the knee related to neuromuscular and central nervous system disorders: systematic review, qualitative study, survey and costing analysis. Health Technol Assess 2016;20:1-262.

35 Owen E. Tuning of ankle foot orthosis footwear combinations for children with cerebral palsy, spina bifida and other conditions. In: Proceedings of the European Society of Movement Analysis in Adults and Children (ESMAC) seminars. Warsaw, Poland, 2004: 23-5.

36 Owen E, Bowers R, Meadows C. Tuning of AFO-footwear combinations for neurological disorders. In: Symposium of the 11th world congress of the International Society for Prosthetics and Orthotics (Invited Presentation, 2004: 1-6.

37 Stallard J, Woollam PJ. Transportable two-dimensional gait assessment: routine service experience for orthotic provision. Disabil Rehabil 2003;25:254-8.

38 Freedom of information act, 2000. Available: http://www.legislation. gov.uk/ukpga/2000/36/contents [Accessed 29 May 2019].

39 Lord M, Foulston J. Surgical footwear: a survey of prescribing consultants. BMJ 1989;299:657. 